\title{
LEGITIMIDAD Y ESPACIO PARA LA DEMOCRACIA EN ERNESTO GARZÓN VALDÉS
}

\author{
José Luis Martí \\ Universitat Pompeu Fabra, Barcelona
}

RESUMEN. En este trabajo se pretende mostrar que la teoría del coto vedado y de la democracia de Ernesto Garzón Valdés, interpretada conjuntamente con su teoría del paternalismo y perfeccionismo, deja un espacio menor para la decisión democrática del que supone la propia teoría. El único espacio de decisión democrática que no supondría la vulneración del coto verdad ni una intromisión perfeccionista sería el de las cuestiones de mera coordinación o las cuestiones simbólicas o expresivas sin ningún tipo de relevancia moral. La única forma en la que Garzón Valdés puede evitar esta conclusión sería admitiendo, contra lo que explícitamente ha sostenido, que existe un espacio para la objetividad relativo al ámbito de lo correcto abierto a la decisión democrática.

Palabras clave: Ernesto Garzón Valdés, democracia, paternalismo, perfeccionismo.

ABSTRACT. The argument in this paper holds that the theory of the "coto vedado" and democracy in Garzón Valdés, as jointly interpreted with his theory of paternalism and perfectionism, leaves a smaller field up to democratic decision than what the theory itself presupposes. The only field up to democratic decision that would not imply the violation of the "coto vedado» nor a perfectionist intromission is the field of the mere coordination or the symbolic or expressive issues with no moral relevance. The only way in which Garzón Valdés can avoid that conclusion is accepting, in contrast with what he has held in the paper, that there is a room for objectivity in respect to the determination of the right up to democratic decision.

Keywords: Ernesto Garzón Valdés, democracy, paternalism, perfectionism. 


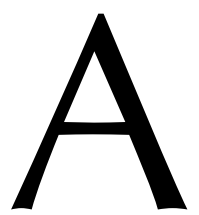

Ernesto GARZÓN VALDÉS hay que rendirle homenaje todos los días. Por ser maestro de todos, por sus numerosas e importantes contribuciones a nuestra filosofía, por la amistad, por su mirada larga y elegante sobre las cosas, o por el estilo, que lo es (casi) todo. Su vida y su obra pueden verse como una lucha constante por hacerse mejor y por hacer mejor el mundo, un doble objetivo que tal vez encuentre su síntesis en la idea de dignidad, que tan cara le ha resultado siempre. Y ello me trae a la memoria una bonita frase que su tan querido Thomas Mann incluye en La muerte en Venecia, y que se ajusta a Ernesto como un guante hecho a medida:

Pero había ganado esa dignidad hacia la cual, en su opinión, todo gran talento se ve impulsado y aguijoneado: sí, hasta podría decirse que toda su carrera había sido una consciente y obstinada ascensión hacia la dignidad, más allá de los mil y un obstáculos interpuestos por la ironía y la duda.

Pero como, a diferencia del libro de Mann, se trata de que esta ascensión continúe, voy a plantear lo que yo llamaría una acotación al margen de su obra, con la pretensión de discutir con Ernesto constructrivamente, como él siempre me ha enseñado a hacer. El trabajo en el que centraré mi discusión es «El consenso democrático: fundamento y límites del papel de las minorías» ${ }^{1}$. En él aparecen varias de las más importantes aportaciones teóricas que Ernesto ha realizado a la filosofía política, como la noción de coto vedado, su relación con la democracia, su concepción del paternalismo justificado, sus ideas sobre el papel del consenso y el disenso, su análisis de la legitimidad y su distinción de la legitimación, etc. Aquí me ocuparé solamente de la cuestión de la democracia y los derechos, y lo haré de un modo parcial y hasta provisional, que debe servir únicamente para señalar lo que desde mi punto de vista puede convertirse en un problema interno en la obra de GARZÓN VALDÉS.

Según GARZÓN VALDÉS, ni la justificación utilitarista ni la epistémica ofrecen argumentos aceptables en favor del valor instrumental de la democracia, o al menos no de una democracia irrestricta ${ }^{2}$. Las decisiones que una autoridad democrática real puede tomar, a las que GARZÓN VALDÉS se refiere como consenso fáctico, pueden no sólo ser ineficientes sino también abiertamente inmorales. Para evitar este riesgo debemos imponer algún tipo de restricción sobre el procedimiento democrático, una restricción que no puede ser interna o subjetiva, es decir, autoimpuesta por medio del propio procedimiento democrático, sino que debe imponerse externa u objetivamente. La propuesta de GARZÓN VALDÉS, como es bien conocido, consiste en trazar un perímetro de protección de derechos al que denomina «coto vedado», un núcleo mínimo sustantivo para la legitimidad. Según dicha propuesta, deben ser excluidos del ámbito de decisión de la democracia parlamentaria «todos aquellos bienes que son considerados como básicos para la realización de todo plan de vida». Para determinar esta lista de bienes es irrelevante la opinión de la mayoría democrática, justamente porque se trata de una restricción externa u objetiva. En este sentido, «está plenamente justificada una actitud

${ }^{1}$ Publicado en Isonomía, n. 12, abril, 2000: pp. 7-34. Las referencias entre paréntesis corresponden siempre a las páginas de este trabajo.

${ }^{2}$ Quiero advertir desde el inicio que, sin perjuicio de lo que sostendré a continuación, comparto con Ernesto la intuición fundamental que expresa este trabajo: la democracia difícilmente puede tener valor si no se garantizan ciertas precondiciones en forma de derechos básicos de todos los ciudadanos. 
paternalista en el caso de que los miembros de la comunidad no comprendan la importancia de estos bienes básicos» (pp. 21-22).

La protección y garantía de los bienes básicos que conforman el coto vedado se establece mediante la institución de derechos básicos, que vienen a coincidir en opinión de GARZÓN VALDÉS, y grosso modo, con las diversas generaciones de derechos humanos habitualmente reconocidas por las declaraciones internacionales y por la mayoría de las constituciones democráticas. Por otra parte, el ámbito que deja abierto a la «negociación y compromiso» parlamentarios, esto es, a la autoridad democrática $^{3}$, es doble: 1) en primer lugar, el del «afianzamiento de la vigencia efectiva de los bienes básicos», es decir, el del cumplimiento de los derechos fundamentales más el despliegue normativo necesario para garantizar dichos bienes básicos; y 2) la toma de decisiones relativa a los «deseos secundarios de la gente, es decir, aquellos que no están relacionados con los bienes primarios» (p. 23). Mi objetivo va a ser el de mostrar que estos dos ámbitos dejan un espacio inexistente o demasiado reducido para la democracia.

Con respecto al primero de ellos, el destinado al respeto y despliegue normativo de los derechos fundamentales, vale decir que el deber de la autoridad jurídica eventualmente democrática consiste en tomar aquellas decisiones políticas que conlleven un mayor respeto y produzcan unos mejores resultados en términos de honrar o maximizar los valores protegidos por tales derechos. El parlamento debe tomar aquellas decisiones que protejan mejor el coto vedado, las correctas o las más correctas en este sentido, y ésta es una cuestión eminentemente técnica. Ahora bien, si excluimos la determinación de los bienes básicos que integran el coto vedado del campo de acción de la autoridad democrática por temor a que sus decisiones puedan ser objetivamente incorrectas, ¿por qué dejar en sus manos la cuestión técnica, mucho más objetivable, de cómo proteger tales valores? Es una cuestión técnica saber si un incremento o una rebaja del impuesto de sucesiones redundará en un mayor dinamismo económico o si ciertos impuestos indirectos desincentivarán la inversión o el consumo y finalmente harán insostenible una determinada redistribución. Estas decisiones no parecen un terreno adecuado para la negociación y el compromiso parlamentarios, al menos desde una perspectiva como la de GARZÓN VALDÉS, al involucrar aspectos técnicos de racionalidad instrumental más objetivos aún que los relativos a la determinación de los valores constitucionales.

Se podría decir, ciertamente, que no son cuestiones técnicas saber si la eutanasia vulnera el derecho fundamental a la vida o si el matrimonio entre personas del mismo sexo es un desarrollo adecuado del derecho constitucional al matrimonio. Pero sigue siendo válido el argumento de la consistencia. Si la determinación de los bienes básicos que integran el coto vedado debe ser excluida a la labor de la autoridad democrática, la interpretación de una formulación abstracta en forma de cláusula constitucional, por ejemplo qué implica en concreto el derecho a la vida, también debe quedar excluida. Porque, ¿qué es la interpretación de dicha formulación abstracta sino justamente la determinación de la lista de bienes básicos por la vía de la concreción?

\footnotetext{
${ }^{3}$ No me ocuparé aquí de la concepción de la democracia que suscribe GARZÓN VALDÉs, una que equipara democracia a negociación y compromiso, que me parece equivocada. Pero ello es irrelevante para mi argumento en este trabajo.
} 
Si esto es así, deberíamos concluir que la autoridad democrática no es apta para cumplir con la primera de las funciones que GARZÓN VALDÉS le encomendaba. El único modo de hacer sentido a esa primera función sería sostener alguna de estas tres tesis, todas ellas, a mi juicio, igualmente implausibles: que a) la autoridad democrática es técnicamente más competente para decidir cómo determinar normativamente ciertos valores que para seleccionarlos en abstracto, esto es, que es más competente para saber si la eutanasia vulnera el derecho a la vida que para instaurar el propio derecho a la vida; que $b$ ) mientras que la determinación de los bienes básicos es objetiva la elección de los mejores medios para garantizarlos es subjetiva, algo tan absurdo como que los valores son objetivos pero que las cuestiones técnicas sobre cómo implementarlos no lo son; o que $c$ ) hay diversas formas todas ellas igualmente eficientes para garantizarlos y dentro de las cuales podemos elegir libremente, lo cual es difícil de creer porque requiere que haya al menos dos estrategias políticas cuya implementación produzca exactamente los mismos resultados, tanto en efectos directos como indirectos, en términos de impacto sobre los derechos. Tal vez ocurra algo así en un caso aislado, pero no alcanzo a comprender cómo podría ocurrir en todos.

De hecho, GARZÓN VALDÉS no se refiere demasiado a esta primera función, y presta mayor atención al segundo espacio de la democracia, el de los intereses o deseos secundarios, plenamente subjetivos ${ }^{4}$, y que según él los representantes deben satisfacer en la medida de lo posible, con el único límite de que ello no interfiera en la provisión de bienes primarios protegida por el coto vedado. Ahora bien, nos podemos preguntar si dichas políticas no suponen una amenaza de perfeccionismo, esto es, una intromisión injustificada en la esfera privada de los individuos. En un esquema liberal de legitimidad política, como el que GARZÓN VALDÉS propone, los derechos de autonomía garantizan un espacio de no intromisión por parte del Estado, establecen una rígida separación entre la esfera pública y privada de los individuos, y entre las concepciones de lo correcto y sus concepciones de lo bueno. Como GARZÓN VALDÉS siempre ha advertido, la acción coercitiva del Estado corre siempre el riesgo de ser paternalista o perfeccionista, es decir, de entrometerse en la esfera privada de los individuos.

Es indudable que no incurrimos en perfeccionismo al imponer un coto vedado de garantía de bienes primarios que actúa como marco y límite de las decisiones democráticas porque, por definición, tales bienes son necesarios para la persecución de cualquier plan de vida, de modo que no pueden implicar la imposición de un plan de vida determinado ${ }^{5}$. Ahora bien, ¿ podemos decir lo mismo con respecto a las políticas que tratan, en palabras de GARZÓN VALDÉS, de «procurar la mayor satisfacción posible de deseos secundarios»? Para responder a esta pregunta debemos comprender mejor lo que son los intereses o deseos secundarios. GARZÓN VALDÉS no proporciona ejemplos

${ }^{4}$ GARZÓN VALDÉS se refiere indistintamente a intereses y deseos secundarios, «aquellos que no están relacionados con los bienes primarios» (p. 23), que a diferencia de los intereses primarios, que son objetivos y por lo tanto independientes de los «deseos y voluntades» de la gente, éstos son subjetivos y completamente dependientes de estos.

5 Y en la medida en que supongan una política paternalista, como en el caso de imponer un sistema educativo obligatorio o un sistema público forzoso de pensiones de jubilación, dicho paternalismo estaría justificado (pp. 21-22). Recordemos que, según la teoría de GARZÓN VALDÉS, mientras que las políticas paternalistas pueden estar justificadas en el caso de los incompetentes básicos que no pueden proteger sus propios intereses, las políticas perfeccionistas que intentan imponer un plan de vida concreto están siempre injustificadas. 
al respecto en este trabajo, pero lo que sí podemos decir es que, dado que se definen en oposición a los bienes primarios, los intereses secundarios deben estar relacionados con lo que podríamos denominar, para salvaguardar la terminología de GARZÓN VALDÉs, bienes secundarios.

Veo algunas dificultades, ya, a la hora de identificar los propios bienes primarios. Hay, a mi modo de ver, dos formas de entender la noción de bien primario, según se interprete la expresión «cualquier plan de vida». Podemos, en primer lugar, entenderla literalmente como «cualquier plan de vida imaginable». Pero este sentido lato tiene el problema de que algunos planes de vida pueden ser tan distintos, $\mathrm{y}$ tan inmorales, incluyendo por ejemplo el plan de vivir en una sociedad en la que no se prohíba el homicidio por la emoción que eso daría a nuestra vida cotidiana, que se hace difícil encontrar bienes que sean necesarios para desarrollar todo plan de vida, y que además el Estado deba proveerlos ${ }^{6}$.

El segundo sentido de la expresión «cualquier plan de vida» no es literal, sino que se refiere implícitamente a cualquier plan de vida «razonable», que descarta el de vivir en una sociedad que no prohíba el homicidio. Aunque esta segunda interpretación tiene el problema de cómo entrar a valorar la aceptabilidad o razonabilidad sustantiva de ciertos planes de vida sin infringir los principios liberales de neutralidad y de separación de la esfera pública y privada. La respuesta liberal a este interrogante debe ser la siguiente. Los planes de vida imaginables quedan filtrados por las reglas que impone el ámbito de lo correcto. No pueden restringirse los planes posibles de vida desde una concepción particular de lo bueno, ya que la neutralidad se predica justamente con respecto a dichas concepciones de lo bueno. Pero las reglas de lo correcto son suficientes para excluir planes como el de querer vivir en una sociedad en la que no se prohíbe el homicidio. Y los bienes primarios serían, pues, aquellos necesarios para todo plan de vida razonable?

Ahora bien, si lo correcto selecciona los planes de vida razonables a partir de los cuáles puedo determinar la lista de bienes primarios, lo correcto termina por coincidir con el ámbito del coto vedado, que es el de protección de dichos bienes primarios. Lo correcto y el coto vedado serían, pues, coextensivos. Y el problema, entonces, es que si el coto vedado queda fuera del alcance de la autoridad democrática y su ámbito es coextensivo con el de lo correcto, por definición los intereses o deseos secundarios pertenecen al ámbito de lo bueno, y el estado liberal no puede intervenir en este campo, a riesgo de cometer una intromisión perfeccionista. Lo cual es todavía peor si recordamos que, según GARZÓN VALDÉs, la autoridad democrática tiene el deber de maximizar la satisfacción de dichos intereses. Si esto es así, no hay espacio para una autoridad

\footnotetext{
${ }^{6} \mathrm{Ni}$ siquiera un bien tan básico como la vida sería un bien primario si partimos de esta primera interpretación. Y nada impide que podamos imaginar planes de vida distintos que vayan prescindiendo de todos y cada uno de los bienes que habitualmente identificamos como primarios. No nos dejemos engañar por juegos de palabras, como el de que la expresión «plan de vida» implica un proyecto de supervivencia y no de muerte. La expresión «plan de vida» puede ser sustituida por «las cosas que yo elijo para mi vida y mi muerte, incluyendo en la medida de mis posibilidades, el contexto que me rodea».

${ }^{7}$ Para evitar, entonces, un posible problema de circularidad, ya que según esta interpretación para determinar los bienes primarios necesito conocer previamente cuál es el ámbito de lo correcto que determina qué planes de vida son razonables, deberíamos contar con un criterio independiente de identificación del ámbito de lo correcto que no recurra a la idea de bienes primarios. Y no encontramos un criterio así en la obra de GARZÓN VALDÉs. Pero no me detendré ahora en este problema.
} 
democrática liberal. O bien la autoridad democrática transgrede la frontera del coto vedado al regular cuestiones relativas a lo correcto, o bien interfiere de manera perfeccionista en la esfera privada de los individuos al regular cuestiones del ámbito de lo bueno. De hecho, para ser más precisos, puesto que parte de los derechos que conforman el coto vedado están destinados a protegernos también de la intromisión perfeccionista en el ámbito de lo bueno, en ambos casos se produce siempre una vulneración del coto vedado. En definitiva, la acción de la autoridad democrática implicaría siempre, por razones conceptuales, una injerencia en el coto vedado. Y el coto vedado ya no sería sólo límite a la acción de la autoridad democrática, sino su propia prohibición ${ }^{8}$.

Veamos un ejemplo de política que satisfaga intereses secundarios (no digamos ya que maximice) sin afectar la asignación de bienes primarios, como el de la provisión de ciertos bienes culturales, por ejemplo, la financiación de la programación de la ópera del Liceu de Barcelona. Que el Estado financie este tipo de actividades, como a GARZÓN VALDÉS y a mí nos parece necesario y deseable para nuestros planes de vida, puede ser el resultado de satisfacer intereses secundarios. Ahora bien, es evidente que muchas personas tienen planes de vida para los que la ópera no tiene ningún valor, y que preferirían a cambio que el Estado financiara los partidos de fútbol o los parques de atracciones. Si la opera es un bien secundario, sobre el que se ciernen intereses secundarios, no veo cómo el Estado puede proveerlo sin privilegiar un plan de vida razonable sobre otros planes de vida razonables, y por lo tanto sin una política en algún grado perfeccionista?.

Y algo parecido sucede, me temo, al plantear nuevos ejemplos: las políticas de medio ambiente, los servicios sociales asistenciales, la red de carreteras e infraestructuras públicas, etc. Los únicos casos que no implican perfeccionismo, y que pueden representar el ansiado espacio intermedio entre lo correcto definido por el coto vedado y la esfera privada de inmunidad de los ciudadanos, son los casos de irrelevancia moral como los de pura coordinación, en los que el Derecho simplemente sirve como clave coordinativa del comportamiento de los ciudadanos. Lo correcto no determina si es mejor conducir por la derecha o por la izquierda, pero los ciudadanos deben elegir un sentido de circulación obligatorio para regular armoniosamente el tráfico. También en este ámbito entrarían los casos de afirmación expresiva de la comunidad política, tales como elegir los colores de una bandera o un himno nacional, o decidir si las selecciones deportivas de las comunidades autónomas pueden competir internacionalmente, etc. Pero, sin negar la importante dimensión simbólica o expresiva de muchos de estos casos, esto implica reducir el ámbito de la democracia a muy pocas cuestiones, y excluir todas las importantes.

Cabe aún otra posibilidad. Tal vez el ámbito del coto vedado no sea coextensivo con el ámbito de lo correcto, como habíamos supuesto, y exista un espacio para una decisión democrática no perfeccionista más allá de estas cuestiones coordinativas y ex-

${ }^{8}$ Esta conclusión es particularmente desesperanzadora si tenemos en cuenta el fenómeno de la expansión del coto vedado, según el cual el ámbito de los bienes primarios tiene fuerza expansiva, como GARZÓN VALDÉs afirma en sus trabajos, en el sentido de que progresivamente nuestras reflexiones éticas nos empujan a dar importancia moral a asuntos que hasta hace poco nos parecían irrelevantes.

${ }^{9}$ Podría decirse que el acceso a la ópera es un bien primario en el sentido de que es un bien necesario para el desarrollo de todo plan de vida razonable, pero entonces quedaría también excluido, como ya hemos visto, del ámbito de decisión de la autoridad democrática. 
presivas. Mientras que la acción del Estado no estaría justificada con respecto a las concepciones de lo bueno, el coto vedado sólo ocuparía una parte de las decisiones relativas al ámbito de lo correcto, dejando las otras en manos democráticas. Pero eso supondría admitir que el ámbito de la decisión democrática abarca algunas cuestiones relativas a los bienes primarios, y por lo tanto trasciende los meros intereses secundarios y subjetivos para adentrarse en el espacio de la objetividad, lo cuál llevaría a GARZÓN VALDÉS a sacrificar otra de sus tesis ${ }^{10}$.

En definitiva, la teoría de GARZÓN VALDÉS parece debatirse ante el siguiente dilema. O bien el coto vedado termina coincidiendo con el ámbito de lo correcto, y entonces la autoridad democrática sólo puede pronunciarse sobre cuestiones de irrelevancia moral, como las puramente coordinativas o las expresivas, a riesgo de ser perfeccionista en caso de extralimitarse, o bien hay un espacio mayor para la democracia que el de los deseos secundarios, un espacio de objetividad que sin embargo está más allá del coto vedado. En cualquier caso, Ernesto debería debilitar o renunciar a alguna de sus tesis.

${ }^{10}$ Podría decirse, para evitar dicha conclusión, que la parte de lo correcto que no queda protegida por el coto vedado no es relativa a bienes primarios sino un espacio de los deseos secundarios. Pero esto la convertiría en subjetiva, y ello parece implausible desde una perspectiva liberal tradicional de lo correcto. 